\title{
TRANSAS E TRANSES: SEXO E GÊNERO NOS CULTOS AFRO-BRASILEIROS, UM SOBREVÔO
}

\author{
PATRICIA BIRMAN \\ Universidade do Estado do Rio de Janeiro
}

\begin{abstract}
Resumo: Através de um percurso na literatura sobre cultos afro-brasileiros, este artigo procura problematizar as formas pelas quais questóes de gênero são tratadas em alguns trabalhos antropológicos recentes. Valoriza particularmente o tratamento que é dado à perspectiva das mulheres a respeito dos conflitos que vivem na esfera da família e a forma por meio da qual integram as entidades 'sobrenaturais' em suas vidas. Discute também de que modo uma perspectiva antropológica objetivista pode dificultar o reconhecimento da construção religiosa que dá sentido a certas relações de gênero.
\end{abstract}

Palavras-chave: possessão, gênero, família, trajetórias, teorias da representação.

Duas dificuldades têm recorrentemente acompanhado os estudos sobre os cultos de possessão no Brasil: uma, quase secular, diz respeito à relação dos pesquisadores com a própria noção de possessão - como compreender essa 'crença' dos indivíduos na realidade da possessão, principalmente as interações entre médiuns e seus santos, deuses e entidades? Um longo percurso separa os pesquisadores de hoje daqueles que associavam esses cultos à irracionalidade e ao primitivismo, sem falar nas interpretações psiquiátricas tão abundantes sobre esse estranho fenômeno. ${ }^{~}$ A segunda dificuldade, mais recente mas não menos relevante, diz respeito aos embaraços que os comportamentos 'pouco convencionais' relativos ao gênero e à sexualidade dos médiuns ${ }^{2}$ têm provocado nas interpretações antropológicas sobre esses cultos. Essas duas dificuldades, de fato, encontram-se intimamente conjugadas. Certos obstáculos que dificultaram a compreensão teórica da possessão se encontram, de fato, associados às dificuldades analíticas enfrentadas pelos pesquisadores diante dos comportamentos 'desviantes' em termos sexuais e de gênero dos seus praticantes nos centros de culto em todo o país.

Copyright (c) 2005 by Revista Estudos Feministas

' Raimundo de Nina Rodrigues, médico baiano, foi o primeiro de uma vasta linhagem de pesquisadores que buscou integrar o fenômeno da possessão em um quadro psiquiátrico (NINA RODRIGUES, 1935).

2 Estou utilizando o termo "médium" ou "filho-de-santo" sem me preocupar com a especificidade que esses termos possuem em certos contextos. O que importa qqui é identificá-los como indivíduos que praticam uma ou mais de uma forma de possessão em qualquer das vertentes reconhecidas no conjunto 'afro-brasileiro'. 
Faz parte do consenso antropológico e sociológico que princípios religiosos de interpretação do mundo são instrumentos poderosos de construção da realidade. Contudo, no caso dos cultos de possessão, há uma evidente discordância entre o que os pesquisadores e religiosos consideram parte integrante do 'real' que os primeiros analisam. A presença de entidades 'na Terra' é 'real' para os religiosos e 'irreal' para os pesquisadores. Essa pequena diferença quanto ao estatuto de realidade dos entes, de absoluta centralidade nessas experiências religiosas, não acontece sem conseqüências analíticas. Grande parte dos trabalhos entre os anos 1960 e 1980 sobre a possessão fala dos médiuns e da complexidade da construção da noção de pessoa nos cultos de possessão, dos mecanismos compensatórios que a mediunidade lhes possibilita (sobretudo no caso das mulheres), mas evitam cuidadosamente considerar como parte da realidade tratada esses 'outros' espirituais que tanto ocupam os médiuns, seus clientes e famílias. ${ }^{3}$

Os espíritos e entidades, digamos, fazem parte da 'pessoa' mas não fazem parte da 'realidade' a ser descrita. A agência descrita, nesse caso, é sempre a do indivíduo, ainda que este insista em afirmar outra coisa e atribua inequivocamente agência aos entes sobrenaturais com os quais interage.

Pretendo neste texto demonstrar que temos tudo a ganhar se adotarmos uma perspectiva analítica que não 'desrealiza' os efeitos e produtos da possessão para os seus praticantes mas que, ao contrário, aceita a condição de agentes que os religiosos atribuem aos seus santos e entidades. Qual o poder que lhes é assim designado? Em que circunstâncias interferem nas relações sexuais, familiares, conjugais de seus médiuns?

Valorizando o ponto de vista dos médiuns e filhos-de-santo, contra as concepções do pesquisador, é possível melhorarmos significativamente a compreensão que temos sobre as relações de gênero e o espaço concedido à sexualidade nesses cultos. Isso porque poderemos olhar com menos constrangimentos teóricos e, quiçá, teológicos as delicadas relações que se tecem quando a prática da possessão entrelaça humanos, deuses e espíritos em tramas que envolvem desejos sexuais, elos afetivos e papéis de gênero com os diferenciais de poder que atravessam todas essas inter-relações.

Vamos, portanto, privilegiar aqui certos trabalhos acadêmicos que conseguiram, ao se aproximarem do ponto de vista dos religiosos, levar a sério, com eles e como eles, a agência que possuem os entes sobrenaturais com os quais desenvolvem vínculos de importância e de natureza variadas. ${ }^{4}$ Talvez assim fique menos obscuro os relatos de religiosos como o de uma senhora, entre inúmeros outros, que fala do que significou para ela ter contado com a intervenção de uma pomba-gira ${ }^{5}$ nas suas relações com o marido, filhos e amantes. O diálogo conflituoso e complexo com a transgressão das normas conjugais e familiares, que muitos médiuns mencionam, têm como um dos seus componentes essenciais

\footnotetext{
${ }^{3}$ Podemos aqui fazer referência a um Colóquio já bem distante no tempo em que essas dificuldades, bem como as principais formas de contorná-las, já se encontravam claramente consolidadas. Trata-se do Colóquio "Cultes de Possession", em 1968, presidido por Roger Bastide e Jean Rouch, que reuniu os pesquisadores mais reconhecidos desse tema pelos seus trabalhos na África e no Brasil. Dos pesquisadores que na época trabalhavam no Brasil, estiveram presentes Roger Bastide, Joana Elbein dos Santos, Gisele Binon-Cossard e Pierre Verger. Pesquisadores reconhecidos mundialmente como Joan Lewis, Erica Bourgignon, Germaine Dieterlen e Luc de Heusch também participaram.

${ }^{4}$ Trata-se dos trabalhos de Stefania CAPONE, 1999; Véronique BOYER, 1993; e Kelly HAYES, 2004. Sobretudo este último, que me inspirou mais claramente neste artigo, não somente apresenta uma análise que suplanta, nessa perspectiva apontada, a literatura sobre os cultos-brasileiros como também explicita uma crítica ao funcionalismo que estaria, em última análise, guiando o conjunto.

${ }^{5}$ Pomba-giras e exus são os termos que designam nos cultos afro-brasileiros entidades geralmente associadas à transgressão eventualmente diabólica. As pomba-giras são, dizem os especialistas, exus femininos. É vasta a literatura sobre esses cultos e na sua maior parte temos descrições sobre esses entes sobrenaturais. Ver especialmente Liane TRINDADE, 1982; e Marcia CONTINS e Marcio GOLDMAN, 1984.
} 
a possessão como o instrumento que permite a intervenção desses personagens sobrenaturais em suas vidas e na de seus parentes e amigos.

Encontramos em alguns trabalhos recentes uma associação entre essas duas perspectivas do trabalho antropológico que estou colocando em relevo: de um lado, o abandono, ao menos na centralidade que possuíram, dos aspectos expressivos e simbólicos desses desdobramentos da pessoa, esses 'outros espirituais', em prol de uma análise que valoriza a perspectiva interpretativa dos religiosos e os aspectos pragmáticos que dela decorrem; de outro lado, a valorização das dimensões de gênero e da sexualidade que são consideradas certamente uma das esferas mais importantes de atuação desses personagens 'irreais', sobretudo exus e pomba-giras.

Façamos então, de início, um rápido percurso em torno das reflexões dos primeiros estudiosos dos cultos de possessão a respeito das relações de gênero, poder e sexualidade que as permeiam.

\section{A possessão e seus efeitos sobre a constituição de gêneros}

Em 1940, Ruth Landes já apontava para a presença de relações de gênero transgressoras nos cultos de possessão que ela observou na Bahia. ${ }^{6}$ Nestes, disse ela, os grupos domésticos tinham um feitio de 'matriarcado' e grande parte deles dava abrigo a 'homossexuais masculinos'. O seu relato etnográfico entrelaça relações de gênero, digamos, pouco usuais, com práticas de possessão e de poder que não se guiavam pela ortodoxia religiosa e moral, reconhecida pelos estudiosos desses cultos. O trabalho precursor de Ruth Landes, não por acaso, provocou reações nos círculos eruditos que, na época, defendiam como genuinamente 'religiosos' aqueles cultos que mais se aproximavam de seus próprios valores, o que incluía imagens positivas de uma cultura negra, de origem africana, moralmente próxima do cristianismo. A contestação incisiva de Arthur Ramos não é difícil de compreender:

Em resumo: as conclusões da Dra. Ruth Landes ressentem-se de erros de observação, de afirmações apressadas e de conceitos falsos ou falseados no concernente à vida religiosa e mágica do Negro no Brasil. É lamentável que algumas dessas conclusões, como, por exemplo, do 'matriarcado' negro e controle da religião pelas mulheres, na Bahia, e do homossexualismo ritual, nos negros brasileiros, já estejam correndo os meios científicos e até anunciadas para publicação em revistas técnicas.

A reação de Ramos coloca em relevo, como vemos, a suposta falsidade do argumento de Landes em relação ao "controle da religião pelas mulheres" e à presença de um "homossexualismo ritual". As casas-de-santo foram tratadas por intelectuais como Arthur Ramos, Edson Carneiro e Roger Bastide, entre outros, como comunidades que, transpostas da África para as periferias ainda rurais das cidades brasileiras, preservavam de suas origens uma harmonia social e moral que era preciso, a todo custo, defender. Um pensamento politicamente correto, isto é, uma defesa intransigente dessas manifestações africanas contra o estigma de que eram objeto, exigia que se reconhecesse a essas comunidades as mesmas qualidades morais asseguradas aos 'brancos' e suas famílias. Recusar os argumentos de Ruth Landes de certo modo era enfrentar com as mesmas armas do 'adversário' os ataques que, na sociedade inclusiva, se fazia aos cultos de possessão como lugares de curandeirismo e de feitiçaria, a serviço de indivíduos mal-intencionados. Uma perspectiva normativa assim se afirmava na construção dessas imagens contrárias aos ataques estigmatizantes de que a população de origem africana era objeto.

6 Patricia BIRMAN, 1995.

7 RAMOS, 1942, p. 189. 
O horizonte moral imposto por essas premissas na descrição dos cultos afro-brasileiros orientava seus estudiosos a valorizarem a face reprodutiva das identidades femininas, o que a princípio os levava a excluir ou, pelo menos, minorar os aspectos desviantes apontados por Ruth Landes. O ideal da maternidade e sua perfeita adequação às relações de gênero fazia das mulheres dessas comunidades terreiros seres um tanto assexuados, dedicados ao trabalho doméstico e subordinados às normas da vida em família e a sua hierarquia patriarcal.

O que Landes descreve já em 1940 é um conjunto de relações sociais e familiares não inteiramente adequado aos valores de seus pesquisadores. As diferenças sociais e morais que mal ou bem interessavam os estudiosos por esse campo garantiram, ao longo de todo o século passado, o interesse de diferentes gerações de pesquisadores. Mulheres poderosas e homossexuais masculinos e femininos construíam famílias-de-santo, que seus defensores, intelectuais da elite brasileira, olhavam repetidamente com candura e romantismo, apagando diligentemente as marcas (em grande medida corporais), bem evidentes, em que sexo, gênero e poder tão facilmente se embricavam nas suas interrelações.

Não é difícil reconhecer as operações cognitivas e ideológicas levadas a cabo para garantir a pureza ao mesmo tempo religiosa e moral dos cultos. Bastava separar constantemente o joio do trigo, isto é, aqueles cultos e casas que correspondiam ao modelo ideal dos outros que, segundo esses critérios aplicados, seriam falsos candomblés, praticados por charlatães e indivíduos ligados ao submundo da contravenção e do crime. O trabalho de classificação (e de purificação) ao qual se dedicou mais de uma geração de estudiosos, com efeito, produziu um modelo de ortodoxia valorizado em muitas casas de candomblé. ${ }^{8}$

No entanto, esse modelo normativo jamais dissipou as suspeitas de transgressão sexual e de gênero mesmo entre aquelas casas que meticulosamente cultivavam uma proximidade identitária com o modelo dominante na sociedade inclusiva. A busca da tradição, presente em certas casas de candomblé, alimentada pelos estudiosos que as freqüentaram, em muitas circunstâncias se mostrou contraditória com certas transgressões de gênero que dentro delas se praticavam. ${ }^{9}$ Mesmo entre as casas de culto que não obtiveram um lugar reconhecido no conjunto restrito de casas tradicionais, esse modelo normativo se encontra presente e convive com práticas mais ou menos transgressoras. No conjunto, tudo isso tem a ver com a persistência de relações estreitas entre erotismo, magia e feitiçaria como pano de fundo presente em inumeráveis narrativas sobre a possessão no Brasil. ${ }^{10}$

Como compreender, em suma, esses aspectos sexuais e de gênero, permanentemente associados à transgressão e que continuam, de certo modo, a pertubar os pesquisadores que se aventuram no campo, sempre um pouco exótico e excitante, dos terreiros de macumba?" Até os anos 1970, não parecia haver qualquer hesitação entre os pesquisadores quanto ao caráter moralmente indigno e pernicioso dessas práticas 'marginais', sempre deslocadas para além das fronteiras dos bons terreiros. A partir de então, iniciou-se uma recuperação positiva dessas relações de gênero e de práticas sexuais 'desviantes'. Não foi por acaso que os estudos nesse campo cresceram acompanhando os efeitos do pós-68, sobretudo pela presença e desenvolvimento dos estudos de gênero, referentes principalmente ao estatuto de mulheres e homossexuais na vida social.

${ }^{8}$ Cf. Os trabalhos de Peter FRY, 1977, 1982 e 2002; Yvonne MAGGIE, 1992; e Beatriz GÓIS DANTAS, 1998, sobre a construção da autenticidade nos cultos afro-brasileiros.

${ }^{9}$ Faço referência aqui a Stefania CAPONE, 1999.

${ }^{10} \mathrm{Cf}$. Yvonne MAGGIE, 1992.

"Para uma análise dessa categoria, cf. MAGGIE, 1992; BIRMAN, 1995; e HAYES, 2004. 
Peter Fry, em 1977, é o primeiro, depois do trabalho pioneiro de Ruth Landes, a falar de sexo e de homossexuais nos cultos afro-brasileiros. O trabalho seguinte é de Leni Silverstein, em 1979, que reafirma e defende, do ponto de vista feminista, o poder social e político das mães-de-santo baianas. ${ }^{12} \mathrm{~A}$ partir dos anos 1980 , o número de pesquisas que exploram essa temática aumenta significativamente. ${ }^{13}$ Não pretendo fazer aqui uma revisão bibliográfica desses trabalhos, mas apontar para alguns desenvolvimentos que mais contemporaneamente se apresentam especialmente interessantes nesse campo.

\section{Tramas e transas}

Em 1991, Jim Wafer descreve uma cena em que ele, pesquisador e antropólogo, beijou uma pomba-gira. Vale a pena reproduzir a sua descrição do acontecido, no primeiro capítulo de seu livro intitulado The Lips of Pomba-Gira:

Você gostaria de me beijar? Ela disse "sim" [...]. Pomba Gira me disse que era a primeira vez que ela beijou uma "matéria". Eu já estava há um bom tempo em contato com exus para saber que eles não esperam que o que dizem seja julgado pelos moldes de uma teoria objetivista do significado. Pode ter sido ou não a primeira vez.

No relato desse beijo trocado com um exu feminino, Jim Wafer reconhece ao exu uma agência que, com uma pontinha de ironia, ele mostra que teria sido negada pelas "premissas objetivistas das teorias da representação". Como ele, inumeráveis filhos-desanto, amantes e/ou maridos de médiuns certamente beijaram as pomba-giras deles/as. Muitos antropólogos, aliás, já nos contaram em seus livros e artigos as dúvidas vividas por seus informantes sobre a veracidade do transe e, em conseqüência, da identidade do sujeito com o qual estavam em relação. Mas a dúvida, quando manifesta pelos religiosos, não exclui a possibilidade do evento; somente questiona a sua ocorrência naquele momento preciso. A inter-relação entre homens e espíritos é o pão de cada dia dos médiuns e do cotidiano das casas religiosas: "abraçou o preto-velho", "soube pelo Caboclo o que Ihe foi feito", "pagou para o Tranca-Rua uma dívida antiga..." e assim por diante, envolvendo certas vezes revelações dramáticas, como, por exemplo, quando uma médium diz que foi "o seu exu" que "matou ela, a amante do seu marido". A agência atribuída aos espíritos em uma grande medida escapou das redes de sentido traçadas pelos antropólogos e junto com esta também se ausentaram desse campo analítico as relações de poder e de gênero nas quais interfere.

Como Jim Wafer chama atenção, os exus, por não partilharem das aflições teóricas e teológicas dos cientistas sociais, não cultivam a espectativa, nos muitos encontros com seus fiéis, que estes os 'des-realizem', apagando a força da sua presença cotidiana e de suas inúmeras intervenções na vida de todos os seus clientes e protegidos.

Inúmeras entidades, aliás, já aconselharam pesquisadores de várias gerações a não ignorarem suas intervenções, para o bem de suas pesquisas. Mais recentemente, os seus conselhos têm sido postos em evidência por pesquisadores: Pablo Séman ${ }^{15}$ chama

\footnotetext{
12 O artigo de Leni Silverstein começa se localizando no movimento feminista: "Os antropólogos participantes do movimento feminista internacional, que vem renascendo nos últimos anos, têm buscado restaurar e reintegrar a experiência das mulheres nos registros etnográficos [...]. Em nossas tentativas de análise dos fenômenos sociais em termos de sex/gender, tornou-se necessário combater uma longa tradição sexista intelectual e social, evidenciada pelo tratamento tendencioso ou pelo menos superficial da mulher na literatura analítica" (SILVERSTEIN, 1979, p. 143).

${ }^{13}$ Marcia CONTINS e Marcio GOLDMAN, 1984; Lorand MATORY, 1988; e Patricia BIRMAN, 1995, entre outros.

${ }^{14}$ WAFER, 1991, p. 3-4. Agradeço a Martijn Vanderport a gentileza de me sugerir essa citação.

15 SÉMAN, 2003
} 
atenção para a forma pela qual o avô de seu entrevistado participa das reuniões de família e ajuda o neto a tomar decisões importantes para o seu futuro profissional. O fato de o avô falar por intermédio de um outro familiar, médium que o incorpora, não altera em nada a importância dos seus conselhos nem o reconhecimento da sua agência nos momentos decisivos da vida familiar, como Séman reconhece. Evangelina Mazur ${ }^{16}$ descreve, em certas famílias espíritas, complicadas relações de parentesco nas quais participam entidades e médiuns. Uma avó, por exemplo, habita com o seu neto e com seu falecido marido, que se incorpora por intermédio do seu neto...

Certas dúvidas que os freqüentadores dos terreiros vivenciam, às vezes de modo dramático, outras, de forma conflituosa, mas sempre de forma afetivamente importante, fazem parte do relato de Jim Wafer, que buscou 'entrar' e participar dos jogos relacionais e afetivos que envolviam seus amigos e informantes. Com quem ele se encontrava, ali, naquela praça, de quem eram os gestos que se misturavam com os seus? Da pomba-gira que queria seduzi-lo, ou do jovem, um possível amante? Ou, dos dois, que se alternavam, passando do transe à transa, operando de modo 'flou' as passagens entre estados de consciência/ inconsciência, de presença/ausência de possessão envolvendo ambos os parceiros? ${ }^{17} \mathrm{~A}$ pequena cena que mencionamos bem como os casos de Mazur e Séman agrupam uma série de temáticas que se apresentam dispersas em trabalhos acadêmicos variados: a 'pessoa' e suas 'entidades'; a 'consciência' e/ou 'inconsciência' no transe; as relações 'sexuais'/ 'conjugais'/'familiares' dos indivíduos com os espíritos; as relações dos pesquisadores com espíritos e seus médiuns; o caráter relativamente transgressor/ambíguo e perigoso dessas relações que mesclam freqüentemente sexo, gênero e poder.

O erotismo bem como os comportamentos referidos por Wafer nos meios homossexuais baianos foram retomados em trabalhos recentes que enfocam principalmente mulheres, seus espíritos, seus maridos, filhos e amantes. Os relatos etnográficos desses relacionamentos permitem nos aproximar da perspectiva dessas pessoas. Estariam longe de compreender suas práticas religiosas como 'visões de mundo' ou 'crenças' em um plano sobrenatural - o que responderia a uma necessidade universal de transcendência, tal como muitos autores concebem a função do 'religioso'. Ao contrário dessa dimensão transcendente atribuída aos cultos vistos como 'crenças', estes, como afirma Véronique Boyer, respondem a perguntas mais prosaicas e mais importantes para seus seguidores:

Se muitas coisas parecem obscuras e inexplicáveis, não cabe aos homens, nem é vantagem para eles, discutir os mistérios da fé. O mais importante para eles é o fato que os espíritos estão ali, em torno dos seres humanos e que intervém a qualquer momento nas suas vidas. A questão principal é então como interpretar os seus conselhos e suas ordens, como viver com eles sem que o curso da existência de seus eleitos não seja modificado de forma irrefletida. ${ }^{18}$

Tampouco seus personagens obedecem às premissas realistas que tradicionalmente informam as análises que têm dominado esse campo de saber. Por isso, como sugere Kelly Hayes,

Uma análise próxima das formas que as narrativas e práticas particulares dos espíritos interagem com, comentam sobre e transformam as vidas dos seus praticantes no nível micro político nos fornece uma importante contribuição neste domínio.

${ }^{16}$ MAZUR, no prelo.

${ }^{17}$ Para uma análise interessante dos estados de consciência na possessão, ver o artigo de Daniel HALPERIN, 1999

${ }^{18}$ BOYER, 1993, p. 21

19 HAYES, 2004, p. 20 
Essa autora sugere de forma mais clara que se integre à 'realidade' descrita pelo pesquisador a realidade tal como concebida pelos religiosos, envolvendo as transas das entidades com as quais a pessoa trabalha:

\begin{abstract}
teorizando a predominância de mulheres e outros grupos marginalizados nestas religióes, a abordagem funcionalista tendeu a tratar a possessão como uma forma de mistificação na qual as forças psicológicas e sociais de maior importância são remodeladas em forma de espíritos. Embora a maior parte dos proponentes desta abordagem reconheça que eles representam a crença em espíritos de uma forma que não é aquela reivindicada por seus participantes (i. é. ancestrais, deidades, espíritos de mortos) e sim como forças sociais em larga escala identificadas pelo pesquisador. Esta operação analítica converte o que - para o analista - seriam relações reais de poder ou conflitos (aqueles ligados à dinâmica familiar, gênero, classe, raça, capitalismo, etc) no que - de novo para o analista - seriam forças simbólicas (espíritos, ancestrais, deidades) a quem se dirigem e trabalham no curso do ritual. ${ }^{20}$
\end{abstract}

\title{
Entre mediadores e personagens
}

As escolhas teóricas dos autores citados permitem assim alargar o campo de estudos das relações de gênero na medida em que vão facilitar uma compreensão não somente dos efeitos que a possessão gera sobre os mediadores com as esferas sobrenaturais mas também sobre os efeitos sociais e políticos engendrados pela presença das 'entidades' na vida social do médium e do seu círculo de relações. Sabemos de trabalhos anteriores que a construção da mediunidade por intermédio da possessão engendra transformações na pessoa e também nos papéis sociais de que participa. Do ponto de vista dos homens, a possessão pode alterar também o papel de gênero, favorecendo a homossexualidade para os indivíduos do sexo masculino que desenvolvem esta modalidade de contato com o sobrenatural que atingiria a sua virilidade. ${ }^{21}$ A atividade religiosa da possessão que 'fabrica' mediadores com a esfera sobrenatural tem efeitos sobre a natureza da pessoa em termos de gênero, 'feminilizando-a' quando se trata de homens e 'empoderando-as' quando se trata de mulheres, o que provocaria, em conseqüência, um permanente diálogo conflitivo dessas pessoas com a norma social e suas possibilidades de transgressão. ${ }^{22}$

Nas histórias de mulheres relatadas por Jim Wafer, Kelly Heyes, Stefania Capone e Véronique Boyer ${ }^{23}$ um denominador comum emerge: a apresentação de relações triangulares envolvendo humanos e 'não-humanos', ou, em outros termos, humanos 'reais' e entes 'irreais' em relações conjugais e/ou eróticas. Apresenta-se nesses trabalhos, eventualmente com uma certa hesitação, um deslizamento em termos do objeto descrito: este deixa de ser o médium e sua realidade 'real' para ser o médium e seus personagens 'irreais' em relação. Com efeito, nas narrativas privilegiadas, as mulheres falam dos conflitos entre elas e seus parceiros (maridos e amantes), entre elas e suas entidades (consideradas

${ }^{20}$ HAYES, 2004, p. 289

${ }^{21}$ LANDES, 1967; BIRMAN, 1995; LEÃO TEIXEIRA, 2000; e MATORY, 1988.

${ }^{22}$ Lorand Matory interpretou a presença de homossexuais nos cultos de possessão como efeito deste 'lugar' de possuído que ocupam os filhos-de-santo, sua existência como uma marca feminina, ou o exercício de um papel feminino no interior da relação conjugal - entidade e médium - que assim se forma. O lugar privilegiado atribuído aos homossexuais nesses cultos (MATORY, 1988; BIRMAN, 1995 e 1997; e LEÃO TEIXEIRA, 2000) pode assim ser mais bem entendido. Se assim podemos compreender melhor a presença homossexual nos cultos de possessão, essas observações não permitem avançar muito no que diz respeito ao papel dessa conjugalidade na vida das pessoas que assumem essa modalidade de vínculo com a esfera 'sobrenatural'.

${ }^{23}$ WAFER, 1991; HEYES, 2004; CAPONE, 1999; e BOYER, 1993. 
em alguns casos como seus maridos) e, finalmente, entre estas últimas e os parceiros (e também familiares) das mulheres. Como descreve Stefania Capone,

Os espíritos - principalmente as pomba-giras - viram então os pivôs de uma reorganização profunda das relações de poder no seio do casal: o aliado invisível outorga sua proteção e seu poder a seu "cavalo" face a um homem que raramente dispõe das mesmas mediações sobrenaturais. Para que o homem seja aceito, ele deverá então se submeter à autoridade do espírito protetor de sua mulher, estabelecendo, na maior parte do tempo, um verdadeiro pacto com o ser invisível. ${ }^{24}$

Nas narrativas dos médiuns, estes, suas entidades e seus cônjuges participam de conflitos amorosos em que ciúme, rivalidade, vingança, humilhação, violência e poder são parte da realidade compartilhada, orientando os comportamentos daqueles que são simultaneamente seus sujeitos e suas vítimas:

Na maior parte dos relatos, a relação entre a mulher e seu espírito protetor, Exu ou PombaGira, é sempre vivida como uma aliança que permite às mulheres de fazerem face à violência ou à traição dos homens. São pois os espíritos que intervém diretamente, nos momentos mais perigosos da existência de seus "cavalos", para os proteger e para punir os culpados.

A vida não é fácil para as mulheres, como elas, mulheres das classes populares, assinalaram às pesquisadoras. Stefania Capone descreve situações em que esse 'empoderamento' das mulheres pela inclusão das entidades em suas relações familiares e conjugais transforma o papel da mulher retirando-a da sua posição de submissão:

A aliança das mulheres com os exus - e sobretudo com as pomba-giras - inverte as suas posições de submissão na vida cotidiana, para impor, através da palavra dos espíritos, suas vontades aos homens. A autoridade sobrenatural, oposta à autoridade masculina, conduz então a uma redefinição dos papéis no casal. ${ }^{26}$

\section{Um outro realismo é possível?}

Ao mesmo tempo que Stefania Capone valoriza a 'triangulação' que marca as relações conjugais e sociais das filhas-de-santo, em certa medida, a dinâmica que a triangulação implica parece se dissolver quando descreve a lealdade extrema da entidade à sua médium. ${ }^{27}$ Nessa dinâmica, os interesses da entidade e do indivíduo parecem se confundir inteiramente. $O$ 'defensor' da mulher deseja somente o que esta também deseja, mas não pode manifestar isso em função da sua posição submissa no interior do casamento. A agência atribuída pelos médiuns às suas entidades desaparece, em conseqüência. Será um teatro cuja multiplicidade de sujeitos, de fato, pode ser reduzida a um só, aquele verdadeiro, tal como o Ocidente estabeleceu definitivamente? Abre-se assim uma porta a favor de uma interpretação mais claramente funcional, que não somente 'desrealiza' a realidade tal como concebida pelos religiosos, mas também a justifica em termos essencialmente pragmáticos: por 'detrás' de uma crença encontraremos sempre uma razão pragmática que justifica a irracionalidade, a irrealidade de seus pressupostos.

\footnotetext{
${ }^{24}$ CAPONE, 1999, p. 181.

${ }^{25}$ CAPONE, 1999, p. 182

${ }^{26}$ CAPONE, 1999, p. 182

${ }^{27}$ Cf. a crítica realizada por HAYES, 2004.
} 
Uma certa resposta a esse questionamento nos é fornecida pela etnografia de Kelly Hayes. Com efeito, o seu trabalho etnográfico, essencialmente centrado na história de vida de uma médium, nos deixa entrever uma ainda maior complexidade dessas relações triangulares vividas pelos religiosos e suas famílias. No caso que Hayes analisa, a médium atribui à sua entidade protetora, a da pomba-gira, o poder de cuidar de si, no interior de uma relação que implica um certo equilíbrio de troca. Não supõe, contudo, como muitos outros médiuns, que a entidade não possua vontade própria, em possível contradição com a sua. Ao contrário, insiste que a vontade pomba-gira é capaz, inclusive, de se diferenciar, em certos momentos, conflituosamente da sua.

O fato de as mulheres terem aceitado trabalhar com suas entidades apresenta-se em inúmeras narrativas como um apoio e também um fardo que elas devem gerir cuidadosamente no interior de relações familiares e conjugais complexas, em que dificuldades de todas as ordens sobrecarregam um cotidiano marcado pela instabilidade. Entre as dificuldades do trabalho de mediunidade encontram-se aquelas que se devem ao fato de as entidades relutarem em 'aceitar' as determinações de sua médium, provocando conflitos familiares que escapam ao controle desta.

A mediunidade, do ponto de vista dessas mulheres, supõe então uma relativa autonomia dessa agência, a entidade incorporada. E as narrativas insistem no quanto é difícil para os indivíduos a gestão dessa autonomia no espaço de circulação do médium. Como sublinha Capone, o seu campo de relacionamentos quando inclui os personagens 'irreais' se transforma. Podemos acrescentar que ele passa a oferecer a seus participantes uma configuração que engendra problemas específicos. O que 'elas', entidades, fazem para proteger seus filhos-de-santo não é algo que possa ser separado dos atributos que as singularizam - seus temperamentos, gostos, moralidades bem como as formas como se relacionam com a família da médium, como cônjuges e filhos, sem falar dos clientes. $O$ que as entidades fazem é algo que a médium precisa obrigatoriamente levar em conta e que, como tudo na vida, precisa ser objeto de cuidados específicos.

Dizer que as mulheres médiuns ganham poder por intermédio da prática da possessão é, pois, uma parte da história. A outra parte, não menos valorizada por elas, diz respeito à idéia que fazem dos seus próprios limites: elas não podem tudo porque o controle sobre estes outros agentes a seu favor é também limitado e submetido a uma lógica que Ihes escapa. As entidades, com seus perfis singulares, vão ser postas em relação com uma outra lógica, aquela das relações sociais que, muitas vezes, elas explicitamente rejeitam. Entre esses fogos cruzados permanentes, no interior dessas relações triangulares complicadas, elas reconhecem a vida que levam como difícil e cheia de obstáculos quase impossíveis de suplantar.

Podemos supor que o cansaço que as relações de possessão provocam nas mulheres, e sobre o qual se queixam, advém desses limites que os médiuns reconhecem relativo ao parco controle que eles detêm sobre o próprio destino. Por maior que seja a vontade de uma pomba-gira de transgredir as normas sociais, de punir os maridos cruéis, de fortalecer o poder de sua protegida contra as imposições destes, ela, a pomba-gira, não consegue 'transigir' com suas próprias características, negar a sua 'natureza' e, menos ainda, operar no interior da dinâmica social que em parte ela desconhece. As entidades 'abrem caminhos' que nem sempre a pessoa pode seguir, 'fecham' outros em momentos inconvenientes, prometem sucesso sem dar ao médium as condições para garanti-lo, punem seus inimigos sem levar em conta, por vezes, que as médiuns, apesar de tudo, precisam deles ao redor de si. A falta de controle da médium em relação aos seres em relação aos quais é mediadora é assim parte da complexidade das relações sexuais, conjugais e familiares em que se vê envolvida. A sexualidade desabrida da pomba-gira, 
seu desejo de vingança, sua fidelidade a qualquer preço provocam comportamentos transgressores da médium que nem sempre ela mesma vê como adequados. O diálogo com a transgressão da norma doméstica e familiar é, pois, nuançado também pelas dimensões conflitivas que as entidades espirituais acirram na vida de seus portadores.

São essas as dificuldades que Kelly Hayes coloca em relevo na etnografia que faz da trajetória de uma mãe-de-santo em uma das periferias do Rio de Janeiro. Como nos relata, a vida de Nazareth, pontuada por traições, vinganças, desequilíbrio emocional e financeiro, está longe de lhe oferecer tudo que ela deseja, apesar dos esforços combinados dela e da pomba-gira, sua protetora. Nazareth, que nos é apresentada com delicadeza e simpatia, é um personagem contraditório: seus desejos e valores não obedecem sempre a uma orientação moral homogênea e suas escolhas sofrem com os limites que a sua condição social lhe impõe. O papel da pomba-gira na vida de Nazareth não parece ser o de inverter as relações de gênero, mas de servir a Nazareth nas suas estratégias de vida. Nestas, parece predominar um equilíbrio precário entre uma adesão às normas dominantes das relações de gênero e comportamentos mais ou menos transgressores em relação a estas. A distância cuidadosamente preservada entre a pomba-gira e a sua médium deixa claro que a identidade malandra, sexualmente sem limites, facilmente associada às chamadas "mulheres da rua" - outro nome atribuído a esses espíritos das pomba-giras -, não se confunde com a sua, embora lhe esteja intimamente associada. Assim, no caso de Nazareth, sabemos que o espírito protegeu a sua casa e o seu casamento, de um lado, e, de outro, ajudou a destruir suas relações conjugais, insuflando seu 'cavalo' à desobediência da hieraquia familiar e seus papéis. Quem se vingou das traições do marido de Nazaré foi a pomba-gira, e quem sinceramente se compadeceu de seu estado miserável e dependente foi Nazareth, que aliás teve de trabalhar muito mais com ele para reequilibrar as finanças domésticas. A sua solidariedade com o marido, que afinal buscava corresponder às suas espectativas como provedor da casa, nem por isso era suficientemente forte para forçá-la a abandonar o seu exu que lhe provia de poder contra a hierarquia de gêneros a que estava submetida. Ao fim e ao cabo, casamento deteriorado, espectativas de vida frustradas e um ganho de autonomia no interior do espaço doméstico cujo preço foi, no entanto, múltiplo: uma de-sexualização das suas relações conjugais, uma perda de status social, uma diminuição dos proventos familiares, acompanhado do fechamento do terreiro e diminuição do poder social da pomba-gira, conseqüência indireta das muitas disputas ao longo da vida conjugal, atravessada por esse 'ménage à trois'.

O esforço de Nazareth, como o de muitas outras mulheres descritas nos textos a que nos referimos, não garante a autonomia desejada de forma ambivalente por elas nem forçosamente as transformações que tanto desejam implementar em suas vidas. Fazem o que podem com os instrumentos que se encontram ao seu alcance. Ao reconhecerem a agência de seus espíritos protetores, de certo modo demonstram que a realidade em que vivem é mais complexa do que o nosso imaginário positivista, como pesquisadores, supõe. Essa realidade possui uma dinâmica que inclui vontades contraditórias no interior do espaço doméstico a gerir: as entidades são assim 'mais uma' entre várias outras vontades mais ou menos tradicionais e transgressoras em relação aos valores familiares. O resultado dessas dinâmicas conflitivas é, finalmente, impossível de ser previsto.

Espaços de afirmação de uma religiosidade cada vez mais periférica, os cultos de possessão colocam em relevo, como podemos depreender desses trabalhos, identidades sexuais e de gênero que transitam entre a adesão à norma sexual e de gênero dominante e a sua transgressão, afirmando, apesar de todos os conflitos, as hesitações e as dificuldades de que 'outros mundos' são possíveis. Os trabalhos antropológicos que busquei valorizar possuem o grande mérito de trazerem para a discussão acadêmica essa 'fatia' da realidade 
que se manteve em parte 'invisível', o que contribuiu para 'des-realizar' a força que esta possui e também diminuir, em decorrência, a complexidade contraditória dos indivíduos que a constroem.

\section{Referências bibliográficas}

BIRMAN, Patricia. Fazer estilo, criando gêneros. Rio de Janeiro: Edições UERJ/Relume Dumará, 1995.

"Os companheiros invisíveis". Revista Estudos Feministas, v. 5, n. 1, p. 233-237, 1997. Resenha.

BOYER, Véronique. Femmes et cultes de possession au Brésil. Les Compagnons invisibles. Paris: L'Harmattan, 1993.

CAPONE, Stefania. La quête de l'Afrique dans le Candomblé. Pouvoir et tradition au Brésil. Paris: Editions Karthala, 1999.

CONTINS, Marcia; GOLDMAN, Marcio. "O caso da Pomba-Gira: religião e violência. Uma análise do jogo discursivo entre umbanda e sociedade". Religião e Sociedade, n. 11 , p. 104-132, 1984.

FRY, Peter. "Mediunidade e sexualidade". Religião e Sociedade, n. 1, p. 105-123, 1977. "Homossexualidade masculina e cultos afro-brasileiros". In: Para inglês ver. Rio de Janeiro: Zahar Editores, 1982. p. 54-73.

"Apresentação". In: LANDES, Ruth. A cidade das mulheres. Rio de Janeiro: Editora da UFRJ, 2002. p. 23-30.

GÓIS DANTAS, Beatriz. Vovó Nagô e Papai Branco: usos e abusos da África no Brasil. Rio de Janeiro: Graal. 1988.

HALPERIN, Daniel. "Memória e 'consciência' em uma religião afro-brasileira: o Tambor de Mina do Maranhão". Religião e Sociedade, v. 19, n. 2, p. 77-102, 1999.

HAYES, Kelly Black. Magic at the Margins: Macumba in Rio de Janeiro. An Ethnographic Analysis of a Religious Life. 2004. Ph.D in History of Religions, University of Chicago.

LANDES, Ruth. A cidade das mulheres. Rio de Janeiro: Civilização Brasileira, 1967.

MAGGIE, Yvonne. Medo do feitiço: relações entre magia e poder no Brasil. Rio de Janeiro: Arquivo Nacional, 1992.

MATORY, Lorand. "Homens montados: homossexualidade e simbolismo da possessão nas religiões afro-brasileiras". In: REIS, João José (Org.). Escravidão e invenção da liberdade. São Paulo: Brasiliense, 1988. p. 215-231.

MAZUR, Evangelina M. "Família e laços familiares em um contexto espiritualista". In: DUARTE, Luiz F. D. et al. (Orgs.). Família e religião. Rio de Janeiro: Contracapa, no prelo.

NINA RODRIGUES, Raimundo. O animismo fetichista dos negros baianos. Rio de Janeiro: Civilização Brasileira, Bib. Div. Científica II, 1896-1900, 1935.

RAMOS, Arthur. A aculturação negra no Brasil. Rio de Janeiro: Biblioteca Pedagógica Brasileira, 1942.

SÉMAN, Pablo. "Considerações de um leitor de Paulo Coelho". In: BIRMAN, Patricia (Org.). Religião e espaço público. São Paulo: Attar, 2003. p. 333-344.

SILVERSTEIN, Leni. "Mãe de todo mundo". Religião e Sociedade, n. 4, p. 143-169, out. 1979.

LEÃO TEIXEIRA, Maria Lina. "Lorogun: identidades sexuais e poder no candomblé". In: MARCONDES DE MOURA, C. Eugênio (Org.). Candomblé: religião de corpo e alma. São Paulo: Pallas, 2000. p. 33-52. 
TRINDADE, Liana. "Exu: reinterpretações individualizadas de um mito". Religião e Sociedade, n. 8, p. 29-36, 1982.

WAFER, Jim. The Taste of Blood: Spirit Possession in Brazilian Candomblé. Philadelphia: University of Pennsylvania Press, 1991.

"Transas" and Trances: Sex and Gender in Afro-Brazilian Cults, an Overview Abstract: Looking through the literature concerning Afro-Brazilian cults, this paper deals with the issue of gender in some recent anthropological studies. Mostly, it raises questions for women in terms of the conflicts between family life and the integration of supernatural entities in their lives. There is also a discussion concerning the way an "objectivistic" anthropology could hamper the recognition of a religious construct which might elucidate some gender relations.

Key Words: Possession, gender, family, trajectories, theories of representation.

414 Estudos Feministas, Florianópolis, 13(2): 403-414, maio-agosto/2005 